\title{
PRÁTICAS ALIMENTARES E INTRODUÇÃO DA ALIMENTAÇÃO COMPLEMENTAR DE LACTENTES EXPOSTOS À TRANSMISSÃO VERTICAL DO HIV
}

\author{
FOOD PRACTICES AND INTRODUCTION OF COMPLEMENTARY FEEDING OF INFANTS EXPOSED \\ TO VERTICAL TRANSMISSION OF HIV
}

\section{Priscila Marino Queiroz ${ }^{a^{*}}$, Paula Cunha Lemos ${ }^{b^{* *}}$, Fábio da Veiga Ued ${ }^{*}$}

\author{
apriscila_pmq@hotmail.com, bpaula.cunha@live.com, cfabio_uftm@hotmail.com \\ *Universidade de São Paulo - São Paulo (SP), Brasil \\ **Universidade Federal do Triângulo Mineiro - Uberaba (MG), Brasil
}

Data de recebimento de artigo: 06/05/2017 Data de aceite do artigo: 01/08/2017

\section{RESUMO}

Introduçáo: A impossibilidade da prática do aleitamento materno por mães HIV positivas contribui para alteraçōes no padrão alimentar de seus filhos nos primeiros meses de vida. Objetivo: Analisar as práticas alimentares de lactentes expostos ao HIV, verificando-se o tipo de aleitamento praticado pelas mães, a diluição e o preparo do leite oferecido, o período e a forma de introduçáo da alimentaçáo complementar, bem como os grupos alimentares oferecidos aos lactentes. Materiais e métodos: Estudo transversal, descritivo, realizado com crianças de 6 a 24 meses de idade. Os dados foram obtidos através de entrevista semiestruturada e consulta ao prontuário. Resultados: Todos os lactentes $(n=32)$ iniciaram o uso da fórmula infantil após o nascimento, entretanto, 18,8\% das mães diluíam a fórmula incorretamente. Não houve relato de aleitamento materno, porém $59,4 \%$ das crianças receberam leite de vaca antes dos doze meses. Em 31,2\% dos casos a alimentação complementar foi introduzida antes do sexto mês, e alimentos como ovos, peixes, legumes e verduras ainda não foram oferecidos a todas as crianças. Além disso, alimentos industrializados fontes de carboidratos simples, sódio e gordura foram introduzidos a partir do quinto mês. Conclusóes: A substituição do leite materno por fórmulas infantis foi adequada. Contudo, evidenciouse inadequação na diluição das fórmulas, introdução inoportuna do leite de vaca e da alimentação complementar, oferta reduzida de leguminosas, carnes, ovos, legumes e verduras, e consumo inapropriado de alimentos industrializados e/ou ultraprocessados nos primeiros meses de vida. Tais práticas contribuem para alteraçôes do estado nutricional e desenvolvimento de doenças crônicas não transmissíveis.

Palavras-chave: HIV; transmissão vertical; alimentação artificial; comportamento alimentar; nutriçáo do lactente.

\section{ABSTRACT}

Introduction: The impossibility of breastfeeding by HIV positive mothers contributes to changes in the dietary pattern of their children in the first months of life. Objective: To analyze the feeding practices of infants exposed to HIV, checking the type of feeding practiced by the mothers, the dilution and preparation of the milk offered, the period and the way of introduction of complementary feeding, as well as the food groups offered to infants. Materials and methods: A cross-sectional, descriptive study performed with children aged 6 to 24 months. The data were obtained through semi-structured interview and medical records. Results: All infants $(\mathrm{n}=32)$ started infant formula after birth, however, $18.8 \%$ of mothers diluted the formula incorrectly. There was no report of breastfeeding, but 59.4\% of the children received cow milk before 12 months of life. In $31.2 \%$ of cases complementary feeding was introduced before the sixth month, and foods such as eggs, fish, and vegetables were not offered to all children. In addition, industrialized foods sources of simple carbohydrates, sodium, and fat were introduced since the fifth month. Conclusions: The replacement of breast milk for infant formulas was adequate. However, there was inadequacy in the dilution of the formulas, inopportune introduction of cow milk and complementary food, reduced supply of legumes, meat, eggs, vegetables, and inappropriate consumption of processed and/or ultraprocessed foods in the first months of life. Such practices contribute to changes in nutritional status and the development of noncommunicable chronic diseases.

Keywords: HIV; vertical infectious disease transmission; bottle feeding; feeding behavior; infant nutrition. 


\section{Introdução}

A transmissão vertical (TV) do HIV (Human Immunodeficiency Virus) pode ocorrer via transplacentária, durante o trabalho de parto e/ou após o parto, através do aleitamento materno ${ }^{1}$. A taxa de prevalência da TV encontra-se entre $25 \%$ e $30 \%$ para os casos em que há ausência de intervenção profilática ${ }^{2}$. Entretanto, através do uso combinado de antirretrovirais (ARV) pela gestante, é possível reduzir para aproximadamente $1 \%$ esse risco, com maior probabilidade de os filhos de mães HIV positivas não serem portadores do vírus ${ }^{2,3}$.

O período intrauterino e o primeiro ano de vida são fases vulneráveis a alteraçôes metabólicas e nutricionais no organismo humano. Assim, a alimentação inadequada do lactente pode acarretar danos à saúde a curto e longo prazo, podendo persistir até a vida adulta ${ }^{4}$. Pautando-se no conhecimento de que a nutrição tem papel primordial no crescimento adequado de qualquer criança, a Organização Mundial da Saúde (OMS) há mais de uma década preconiza o aleitamento materno exclusivo até os seis meses de vida para crianças saudáveis, aliado à alimentação complementar balanceada e equilibrada a partir do sexto mês ${ }^{5}$. Entende-se por alimentaçáo complementar todo e qualquer outro alimento que náo seja o leite materno oferecido ao lactente ${ }^{6}$.

$\mathrm{A} \mathrm{OMS}^{7}$ também informa que as intervençóes com ARV para máes infectadas e crianças expostas ao HIV podem reduzir significativamente o risco de transmissão pós-natal do vírus através da amamentação, sendo liberado o aleitamento nesses casos. Assim, a OMS recomenda que as autoridades nacionais de cada país decidam qual a prática alimentar a ser seguida, ou seja, permitir a amamentação mediante tratamento com ARV para o binômio mãe-filho, ou evitar totalmente o aleitamento materno, desde que a população tenha acesso aos substitutos ideais do leite humano (LH) ${ }^{7}$.

No Brasil, o Ministério da Saúde, através da portaria da Secretaria Nacional de Assistência à Saúde no 97, de 28 de agosto de $1995^{\circ}$ preconiza a não amamentaçáo e/ ou doação de LH pelas mães HIV positivas. Dessa forma, o lactente exposto ao HIV tem direito de receber do governo o leite artificial durante os seis primeiros meses de vida. Leites modificados, ou fórmulas infantis, são os substitutos ideais do leite materno e fornecem energia, proteínas, carboidratos, lipídios, vitaminas, minerais e demais nutrientes, em proporçóes similares ao $\mathrm{LH}^{2}$.

Porém, é necessário que os cuidadores sejam instruídos quanto aos métodos corretos de preparo (diluição), administração e armazenamento das fórmulas infantis. A manipulação inadequada confere um risco cinco vezes maior para a criança de contrair infecção bacteriana, sendo vinte vezes maior se a higiene for precária ${ }^{7}$. Ressalta-se que a imaturidade do sistema imunológico, associada aos efeitos imunossupressores do HIV, expóe essas crianças a maiores adversidades mediante o consumo de alimentos contaminados. A diluição incorreta também se torna um agravante do estado nutricional, que pode acarretar perda e/ou ganho excessivo de peso ${ }^{6,9}$.

A partir do sexto mês de vida o bebê necessita de uma alimentação diversificada, adequada em macro e micronutrientes, capaz de suprir suas necessidades diárias, garantir o crescimento, diminuir as carências imunológicas decorrentes do leite artificial, e reduzir os efeitos colaterais provocados pelos medicamentos ${ }^{7,9}$. A introdução de alimentos ultraprocessados, por sua vez, aumenta os riscos de manifestaçôes alérgicas, distúrbios gastrointestinais e ganho excessivo de peso ${ }^{6,9,10}$. Assim, observa-se que a alimentação nessa faixa etária se torna complexa e exige maior atenção dos cuidadores?.

Tais evidências têm implicações importantes sobre como as mulheres que vivem com HIV podem alimentar seus bebês e como os profissionais da saúde devem aconselhar essas mães. A investigação da alimentação desses lactentes tem sido pouco estudada no Brasil. Diante do que foi apresentado, este estudo tem por objetivo analisar as práticas alimentares de lactentes expostos à transmissão vertical do HIV, verificando-se o tipo de aleitamento praticado pelas mães, a diluição e o preparo do leite oferecido, o período e a forma de introdução da alimentação complementar, bem como os grupos alimentares oferecidos aos lactentes.

\section{Materiais e métodos}

Trata-se de um estudo observacional transversal, descritivo, com abordagem quantitativa. $\mathrm{O}$ estudo foi desenvolvido no Ambulatório Central de Pediatria da Universidade Federal do Triângulo Mineiro (UFTM), em conjunto com as atividades da especialidade de infectologia pediátrica. Esse ambulatório tem caráter regional, sendo responsável pelo atendimento de pacientes de 27 municípios da macrorregião do Triângulo Sul, do estado de Minas Gerais. A pesquisa está cadastrada e aprovada pelo Comitê de Ética em Pesquisa da UFTM, sob o parecer $n^{\circ}$ 677.168.

\section{População do estudo}

A casuística é caracterizada por uma amostra de conveniência. Nesta pesquisa a população foi composta por crianças entre 6 e 24 meses de idade expostas à transmissão vertical do vírus HIV e suas respectivas mães, atendidas no Ambulatório Central de Pediatria, na especialidade de infectologia pediátrica, no período de agosto de 2014 a fevereiro de 2015, e que aceitaram participar da pesquisa. 
Foram adotados os seguintes critérios de exclusão: crianças cujas mães são portadoras de outras doenças infecciosas além do HIV, como toxoplasmose, sífilis, hepatite e citomegalovírus, e/ou que tenham apresentado alguma intercorrência gestacional, como diabetes, pré-eclampsia e eclampsia; além de crianças que possuíam diagnóstico confirmado de infecção pelo HIV.

\section{Procedimento para coleta de dados}

Todos os participantes incluídos no estudo, após serem devidamente informados sobre a pesquisa, foram convidados a participar mediante assinatura do Termo de Consentimento Livre e Esclarecido. Para coleta das informações, as mães foram entrevistadas antes da consulta médica e nutricional por um entrevistador previamente treinado. A entrevista foi realizada em sala ambulatorial privativa, para que houvesse sigilo e confidencialidade dos dados.

$\mathrm{O}$ instrumento da pesquisa consistiu em um questionário semiestruturado elaborado com linguagem clara e objetiva, aplicado diretamente às mães das crianças, abordando questóes socioeconômicas como idade, estado civil, renda familiar, ocupação, escolaridade, moradia, número de gestaçóes, uso de drogas, realizaçáo de pré-natal e orientaçóes sobre o risco do aleitamento materno. Foram investigadas também questóes pertinentes à alimentaçáo da criança, como o tipo de leite oferecido (materno, fórmula infantil ou leite de vaca náo modificado), método de diluição e preparo do leite, adição de carboidratos simples e/ou complexos (achocolatado, açúcar ou cereais) ao leite, período de introdução da alimentação complementar, forma de preparo das refeiçóes, grupos alimentares, temperos e líquidos introduzidos, e mês da introdução de cada alimento.

Para verificar se a diluição das fórmulas infantis ou do leite de vaca não modificado estava adequada, os dados obtidos na entrevista foram confrontados com os da prescrição médica e nutricional no prontuário do paciente. Devido à ampla variação nas preparaçóes envolvendo fórmula infantil ou leite de vaca em pó, referente à diluição e adição de carboidratos, cada preparação foi avaliada individualmente. Para verificar os alimentos introduzidos na alimentaçáo complementar e o respectivo mês de introdução, optou-se por dividir os lactentes em menores e maiores de doze meses de idade, visto que as práticas alimentares variam após um ano de vida.

\section{Análise estatística}

A análise estatística foi realizada empregando-se o aplicativo Statistical Package for the Social Sciences (SPSS), versão 16.0. Para a análise univariada de variáveis categóricas, os dados foram apresentados através de tabelas de frequência (número absoluto e percentual).
Para a análise univariada de variáveis numéricas contínuas, que apresentaram distribuição normal, os resultados foram expressos segundo a média \pm desvio-padrão.

\section{Resultados}

Participaram da pesquisa 32 crianças expostas à transmissão vertical do HIV e suas respectivas mães. A média de idade das crianças foi de 13,25 $\pm 6,9$ meses, sendo $56,2 \%(\mathrm{n}=18)$ do sexo feminino, enquanto a média de idade das mães foi de $26,8 \pm 6,2$ anos. Para $62,5 \%$ $(n=20)$ das mães essa foi a primeira gestação com o diagnóstico de HIV positivo; 96,9\% $(\mathrm{n}=31)$ realizaram o pré-natal, com uma média de 7,47 $\pm 2,0$ consultas; e $37,5 \%$ diagnosticaram o HIV durante as consultas de pré-natal. A média da idade gestacional no momento do parto foi de $37,7 \pm 2,6$ semanas, e verificou-se que $81,2 \%(n=26)$ das crianças nasceram a termo.

Ainda em relação às características maternas, 28,1\% $(\mathrm{n}=9)$ são solteiras, viúvas ou separadas; 71,9\% $(\mathrm{n}=23)$ cuidam do lar ou estão desempregadas; $81,2 \%(\mathrm{n}=26)$ apresentam a renda familiar entre um e cinco salários-mínimos; $59,4 \%(\mathrm{n}=19)$ possuem entre quatro e oito anos de estudo; e 37,5\% ( $n=12)$ utilizaram drogas durante a gestação (incluindo o consumo de cigarro, álcool, ou ambos, além de substâncias ilícitas). A respeito dos dados de moradia, todas as famílias possuíam energia elétrica e geladeira no domicílio, e 96,9\% ( $n=31)$ dispunham de água encanada e rede de esgoto. As características gerais da população do estudo estão descritas na Tabela 1.

Tabela 1: Características das mães e dos lactentes expostos ao HIV segundo as variáveis socioeconômicas e demográficas. Uberaba/MG, 2015. $(n=32)$

\begin{tabular}{lc} 
Variáveis & n (\%) \\
\hline Idade da mãe & $3(9,4)$ \\
$<20$ anos & $29(90,6)$ \\
$\geq 20$ anos & \\
\hline Idade da criança & $16(50)$ \\
$<12$ meses & $16(50)$ \\
$\geq 12$ meses & $9(28,1)$ \\
\hline Estado civil da mãe & $23(71,9)$ \\
\hline Solteira, viúva ou separada & \\
Casada ou em relação estável & $23(71,9)$ \\
\hline Ocupaçáo materna & \\
\hline Do lar ou desempregada & \\
\hline
\end{tabular}

continua... 
Tabela 1: Continuação.

\begin{tabular}{|c|c|}
\hline Variáveis & n $(\%)$ \\
\hline Trabalha ou estuda em meio período & $5(15,6)$ \\
\hline Trabalha ou estuda em período integral & $4(12,5)$ \\
\hline \multicolumn{2}{|l|}{ Renda familiar } \\
\hline$\leq 1$ salário-mínimo & $5(15,6)$ \\
\hline 1 - 5 salários-mínimos & $26(81,2)$ \\
\hline 6-10 salários-mínimos & $0(0,0)$ \\
\hline 11 - 20 salários-mínimos & $1(3,1)$ \\
\hline \multicolumn{2}{|l|}{ Escolaridade da máe } \\
\hline$<4$ anos & $0(0,0)$ \\
\hline $4-8$ anos & $19(59,4)$ \\
\hline $9-12$ anos & $7(21,9)$ \\
\hline$>12$ anos & $6(18,8)$ \\
\hline \multicolumn{2}{|l|}{ Época do diagnóstico do HIV } \\
\hline Antes da gravidez & $16(50)$ \\
\hline Durante o pré-natal & $12(37,5)$ \\
\hline No momento do parto & $4(12,5)$ \\
\hline \multicolumn{2}{|l|}{ Uso de drogas na gestação } \\
\hline Cigarro & $3(9,4)$ \\
\hline Álcool & $5(15,6)$ \\
\hline Cigarro + álcool & $3(9,4)$ \\
\hline Drogas ilícitas & $1(3,1)$ \\
\hline \multicolumn{2}{|l|}{ Dados de moradia } \\
\hline Água encanada & $31(96,9)$ \\
\hline Esgoto & $31(96,9)$ \\
\hline Energia elétrica & $32(100,0)$ \\
\hline Geladeira & $32(100,0)$ \\
\hline
\end{tabular}

Fonte: Elaborada pelos autores (2015).

Todas as mães $(\mathrm{n}=32)$ relataram que receberam orientação dos profissionais de saúde para não amamentar. No momento da entrevista foram identificadas duas crianças que receberam leite materno pelo menos uma vez, entretanto, esse leite advinha do Banco de Leite Humano do município, por doação de outra nutriz. Quanto à utilização de fórmula infantil, todas as crianças $(n=32)$ receberam esse substituto do leite materno, preparado com água filtrada ou fervida, cuja introdução ocorreu já no primeiro mês de vida.

O consumo de leite de vaca não modificado, em pó ou fluido, foi introduzido para $59,4 \%$ das crianças $(n=19)$. Dentre estas, 94,7\% ( $\mathrm{n}=18)$ receberam leite fluido e apenas uma recebeu leite em pó. O leite integral era oferecido para $53,1 \%(\mathrm{n}=17)$ dos lactentes. Além disso, havia duas mães que diluíam o leite de vaca fluido na proporção de 1:1. A água utilizada na preparação e diluição do leite de vaca (pó ou fluido) era fervida ou filtrada. A introdução do leite de vaca ocorreu antes dos doze meses de idade para todos os casos ( $\mathrm{n}=19)$, em média com 10,3 $\pm 5,7$ meses.

Ressalta-se que o principal recurso utilizado para oferecer o leite foi a mamadeira $(84,4 \%)$, e $78,1 \%$ das crianças utilizavam chupeta. Houve mães $(31,2 \%)$ que introduziram a alimentação complementar antes dos seis meses de idade, e $90,6 \%(n=29)$ ofereceram os primeiros alimentos sob a consistência de papa. Na Tabela 2 estáo descritos os tipos de aleitamento e as práticas alimentares adotadas pelas máes.

Tabela 2: Características do tipo de aleitamento praticado pelas mães e das práticas alimentares de lactentes expostos ao HIV até 24 meses de idade. Uberaba/MG, 2015. ( $\mathrm{n}=32)$

\begin{tabular}{lc} 
Variáveis & n (\%) \\
\hline Oferta de leite materno & $0(0,0)$ \\
\hline Da própria mãe & $2(6,2)$ \\
Do Banco de Leite Humano & \\
\hline Uso de fórmula infantil & $32(100,0)$ \\
\hline Sim & $0(0,00)$ \\
\hline Não & \\
\hline $\begin{array}{l}\text { Água utilizada para preparo/diluiçáo da fórmula } \\
\text { infantil }\end{array}$ & $18(56,2)$ \\
\hline Fervida & $14(43,8)$ \\
Filtrada & $0(0,0)$ \\
Não tratada & \\
\hline $\begin{array}{l}\text { Uso de leite de vaca náo modificado (pó ou } \\
\text { fluido) }\end{array}$ & $19(59,4)$ \\
Sim & $13(40,6)$ \\
Não &
\end{tabular}

Tipo de leite de vaca não modificado (pó ou fluido)

Integral

$17(53,1)$

Desnatado

$2(6,2)$

Água utilizada para preparo/diluiçấo do leite de vaca

Fervida

$1(3,1)$

Filtrada

$2(6,2)$

Nâo tratada

$0(0,0)$

continua... 
Tabela 2: Continuação.

\begin{tabular}{lc} 
Variáveis & n (\%) \\
\hline Utensílio no qual recebia o leite & $27(84,4)$ \\
\hline Mamadeira & $5(15,6)$ \\
Copinho & \\
\hline Uso de chupeta & $25(78,1)$ \\
\hline Sim & $7(21,9)$ \\
\hline Não & \\
\hline Introduçáo da alimentaçáo complementar & $0(0,0)$ \\
\hline Antes de 3 meses & $10(31,2)$ \\
De 4 a 5 meses & $22(68,8)$ \\
\hline A partir de 6 meses & \\
\hline Consistência dos alimentos na introduçáo da \\
alimentaçáo complementar
\end{tabular}

Fonte: Elaborada pelos autores (2015).

Quanto à diluição das fórmulas infantis, observou-se inadequação no preparo das fórmulas de 18,8\% das crianças. Em relaçáo ao acréscimo de carboidrato simples e/ou complexo, $93,8 \%$ das mães $(n=30)$ não adicionavam novos ingredientes às fórmulas infantis. Para as crianças que receberam leite de vaca $(n=19)$, o acréscimo de carboidrato simples e/ou complexo foi mais frequente, sendo que $18,8 \%(n=6)$ das mães acrescentavam achocolatado e 15,6\% ( $n=5)$ acrescentavam cereais (Tabela 3).

Tabela 3: Frequência e porcentagem de adequação da diluição e do acréscimo de carboidratos em fórmula infantil e leite de vaca não modificado, consumidos por lactentes expostos ao HIV. Uberaba/MG, 2015. $(\mathrm{n}=32)$

\begin{tabular}{lr} 
Variáveis & $\mathbf{n}(\%)$ \\
\hline Fórmula infantil - diluiçáo & \\
Adequado & $26(81,2)$ \\
Diluído & $3(9,4)$ \\
Concentrado & $3(9,4)$ \\
\hline & continua...
\end{tabular}

Tabela 3: Continuação.

\begin{tabular}{lc} 
Variáveis & n (\%) \\
\hline Fórmula infantil - acréscimos & \\
\hline Açúcar, cereais e achocolatado & $0(0,0)$ \\
Açúcar e cereais & $0(0,0)$ \\
Açúcar e achocolatado & $1(3,1)$ \\
Açúcar & $0(0,0)$ \\
Cereais e achocolatado & $0(0,0)$ \\
Cereais & $0(0,0)$ \\
Achocolatado & $1(3,1)$ \\
Sem acréscimos & $30(93,8)$ \\
\hline Leite de vaca náo modificado em pó - diluiçáo & \\
\hline Adequado & $0(0,0)$ \\
Diluído & $1(3,1)$ \\
Concentrado & $0(0,0)$ \\
\hline Leite de vaca não modificado fluido - diluiçáo & \\
\hline Diluiçáo de 1:1 & $6(18,8)$ \\
Diluição de 1:2 & $2(6,2)$ \\
Sem diluição & $0(0,0)$ \\
\hline Leite de vaca - acréscimos & $16(50,0)$ \\
\hline Açúcar, cereais e achocolatado & $0(0,0)$ \\
Açúcar e cereais & $0(0,0)$ \\
Açúcar e achocolatado & $1(3,1)$ \\
Açúcar & \\
Cereais e achocolatado & \\
\hline Achocolatado & \\
\hline
\end{tabular}

Fonte: Elaborada pelos autores (2015).

A análise dos alimentos introduzidos na alimentação complementar e do respectivo mês de introdução evidenciou que, das crianças menores de doze meses, todas já ingeriram alimentos dos grupos dos cereais e das frutas. Por outro lado, a introdução de leguminosas, carnes, ovos, legumes e verduras não foi concretizada para todos os lactentes. O óleo utilizado durante o ato de cozinhar e o sal acrescentado às papas estiveram presentes na alimentação de $75 \%$ das crianças $(n=24)$. Quanto ao período de introdução dos alimentos, água, chá e açúcar apresentaram a introdução mais precoce, enquanto os demais foram introduzidos, em média, entre o quinto $\mathrm{e}$ o sexto mês de vida (Tabela 4). 
Com relação às crianças maiores de doze meses, todas já receberam suco natural, alimentos dos grupos dos cereais, leguminosas e frutas, além de carne de vaca e frango. Também houve relato da utilização de óleo no preparo dos alimentos por todas as mães. Por outro lado, há lactentes que ainda não consumiram ovos, peixes, legumes e verduras. Observa-se também que o consumo de alimentos industrializados e/ou ultraprocessados esteve presente na alimentação de mais de $50 \%$ das crianças, com média de introduçáo anterior a um ano de vida.

Tabela 4: Quantidade de crianças (\%) e mês de introdução (média \pm dp) de líquidos, alimentos e temperos consumidos por lactentes expostos ao HIV. Uberaba/MG, 2015.

\begin{tabular}{|c|c|c|c|c|}
\hline \multirow{2}{*}{$\begin{array}{l}\text { Líquidos, alimentos e temperos } \\
\text { consumidos }\end{array}$} & \multicolumn{2}{|c|}{$<12$ meses $(\mathrm{n}=16)$} & \multicolumn{2}{|r|}{$\geq 12$ meses $(n=16)$} \\
\hline & n (\%) & $\begin{array}{l}\text { Mês de introduçáo } \\
\quad(\text { média } \pm \text { dp) }\end{array}$ & n (\%) & Mês de introduçáo (média \pm dp) \\
\hline Água & $16(100,0)$ & $1,56 \pm 1,1$ & $16(100,0)$ & $3,06 \pm 2,3$ \\
\hline Chá & $8(50,0)$ & $3,0 \pm 2,5$ & $11(68,8)$ & $3,27 \pm 2,4$ \\
\hline Suco natural & $11(68,8)$ & $5,2 \pm 2,3$ & $16(100,0)$ & $5,7 \pm 1,3$ \\
\hline Cereais, pães, massas, tubérculos e raízes & $16(100,0)$ & $5,9 \pm 0,5$ & $16(100,0)$ & $6,12 \pm 0,8$ \\
\hline Leguminosas & $12(75,0)$ & $6,1 \pm 0,8$ & $16(100,0)$ & $6,1 \pm 0,9$ \\
\hline Carne de vaca & $13(81,2)$ & $5,5 \pm 0,8$ & $16(100,0)$ & $6,6 \pm 2,1$ \\
\hline Carne de frango & $13(81,2)$ & $5,9 \pm 0,7$ & $16(100,0)$ & $6,6 \pm 2,1$ \\
\hline Carne de porco & $1(6,2)$ & $6,0 \pm 0,0$ & $6(37,5)$ & $10,0 \pm 3,1$ \\
\hline Carne de peixe & $4(25,0)$ & $6,0 \pm 0,0$ & $11(68,8)$ & $7,5 \pm 2,9$ \\
\hline Ovos & $3(18,8)$ & $6,6 \pm 1,1$ & $14(87,5)$ & $8,2 \pm 3,8$ \\
\hline Legumes & $13(81,2)$ & $6,0 \pm 0,8$ & $15(93,8)$ & $6,0 \pm 0,8$ \\
\hline Verduras & $11(68,8)$ & $5,7 \pm 0,4$ & $15(93,8)$ & $6,8 \pm 2,2$ \\
\hline Frutas & $16(100,0)$ & $5,4 \pm 1,3$ & $16(100,0)$ & $5,5 \pm 1,2$ \\
\hline Óleo para cozinhar & $12(75,0)$ & $5,9 \pm 0,8$ & $16(100,0)$ & $7,0 \pm 2,1$ \\
\hline Doces & $4(25,0)$ & $5,5 \pm 1,9$ & $11(68,8)$ & $10,2 \pm 4,4$ \\
\hline Frituras & $2(12,5)$ & $5,5 \pm 0,7$ & $10(62,5)$ & $9,4 \pm 5,1$ \\
\hline Embutidos & $2(12,5)$ & $6,5 \pm 2,1$ & $8(50,0)$ & $12,4 \pm 7,2$ \\
\hline Bolacha recheada & $3(18,8)$ & $6,0 \pm 1,0$ & $15(93,8)$ & $9,1 \pm 4,1$ \\
\hline Salgados & $2(12,5)$ & $6,8 \pm 0,7$ & $11(68,8)$ & $13,2 \pm 6,5$ \\
\hline Salgadinhos & $3(18,8)$ & $6,7 \pm 1,5$ & $13(81,2)$ & $10,5 \pm 3,7$ \\
\hline Refrigerante & $1(6,2)$ & $5,0 \pm 0,0$ & $12(75,0)$ & $11,6 \pm 3,8$ \\
\hline Suco artificial & $5(31,2)$ & $6,0 \pm 3,1$ & $12(75,0)$ & $8,4 \pm 5,0$ \\
\hline Macarrão instantâneo & $4(25,0)$ & $6,5 \pm 1,3$ & $14(87,5)$ & $10,5 \pm 3,6$ \\
\hline Açúcar & $5(31,2)$ & $4,4 \pm 2,3$ & $9(56,2)$ & $7,7 \pm 5,3$ \\
\hline Mel & $0(0,0)$ & - & $3(18,8)$ & $7,3 \pm 4,1$ \\
\hline Sal & $12(75,0)$ & $5,9 \pm 0,8$ & $15(93,8)$ & $6,2 \pm 1,1$ \\
\hline Tempero industrializado & $4(25,0)$ & $6,0 \pm 0,8$ & $11(68,8)$ & $9,0 \pm 4,4$ \\
\hline Alho & $10(62,5)$ & $5,7 \pm 0,5$ & $16(100,0)$ & $6,8 \pm 2,0$ \\
\hline Cebola & $9(56,2)$ & $5,6 \pm 0,5$ & $13(81,2)$ & $12,7 \pm 3,0$ \\
\hline Pimenta & $0(0,0)$ & - & $0(0,0)$ & - \\
\hline Temperos naturais & $5(31,2)$ & $5,6 \pm 0,5$ & $12(75,0)$ & $7,1 \pm 2,5$ \\
\hline
\end{tabular}

Fonte: Elaborada pelos autores (2015). 


\section{Discussão}

Os hábitos e práticas alimentares infantis estão diretamente relacionados às condiçóes socioeconômicas da família, as quais podem ser influenciadas pela situação conjugal, pelo nível de escolaridade dos pais, pelas taxas de desemprego, entre outras variáveis. Nos dias atuais, há ainda a crença de que mulheres infectadas pelo HIV sejam solteiras e promíscuas, e que não frequentam os serviços de saúde ofertados à população. Entretanto, dados deste estudo, assim como da Secretaria de Vigilância em Saúde ${ }^{11}$, desmistificam essa crença, evidenciando que há uma década se nota maior percentual de mulheres soropositivas casadas ou que mantêm relação estável e que frequentam os serviços de saúde.

De acordo com o Fundo das Nações Unidas para a Infância (Unicef) ${ }^{12}$, a quantidade de mães adolescentes infectadas ainda é elevada no Brasil, e muitas mulheres não têm acesso ao pré-natal de qualidade, principalmente na regiáo Nordeste do país. Em contrapartida, verificamos um maior percentual de mães adultas, cuja maioria realizou o mínimo de consultas do pré-natal, não utilizou drogas lícitas ou ilícitas e não teve parto prematuro. Tal fato talvez se justifique pela localizaçáo do município onde foi realizada a pesquisa, em uma regiáo desenvolvida no Sudeste do país, com melhor acesso aos serviços de saúde.

Por outro lado, apesar da vivência em uma regiáo avançada do Brasil, ainda se observa um elevado percentual de mães desempregadas ou que cuidam apenas do lar. Como demonstrado no documento Implicaçóes éticas do diagnóstico e da triagem sorológica do $H I V^{13}$, as maiores taxas de infecção pelo vírus estão entre as populaçóes mais pobres e menos escolarizadas. Nota-se um quadro de vulnerabilidade social, o que justifica a necessidade de as políticas públicas garantirem a doação de fórmulas infantis a essa população. Já a presença de água encanada, esgoto, energia elétrica e geladeira na maioria dos domicílios demonstra evolução da infraestrutura de moradia da população, proporcionando melhores condiçóes de preparo e armazenamento das fórmulas infantis, como observado em estudos prévios ${ }^{14}$.

Segundo o Programa Nacional de DST e Aids ${ }^{15}$, o Pacto pela Saúde, aprovado pelo Conselho Nacional de Saúde (CNS) em fevereiro de 2006, fortalece a gestão compartilhada entre os diversos níveis de governo (municipal, estadual e federal). Um dos três eixos do Pacto pela Saúde é o Pacto pela Vida, em que a redução da mortalidade materna e infantil é prioridade básica. Dentre os componentes para a execução dessa prioridade está a redução das taxas de transmissão vertical do HIV.

Uma das formas de evitar a TV é orientar a população sobre os riscos da amamentação para os filhos de mulheres
HIV positivas. Neste estudo verificou-se que tal política vem sendo corretamente divulgada pelos profissionais da saúde, tendo em vista que todas as mães relataram não ter amamentado, pois foram orientadas e informadas sobre a necessidade da introduçáo das fórmulas infantis logo no primeiro dia de vida. Em outro estudo com crianças expostas ao $\mathrm{HIV}^{14}, 90 \%$ das mães foram orientadas a não amamentar, o que demonstra que houve evoluçáo no repasse de informaçóes às mulheres HIV positivas.

Quanto ao preparo das fórmulas, a quantidade de mães que diluíam erroneamente foi preocupante. A diluiçáo inadequada contribui para perda ou ganho excessivo de peso da criança, além de quadros de diarreia ou constipação, em decorrência da alta osmolaridade ou do excesso de pó, respectivamente. Também não é aconselhado diluir o leite de vaca fluido, seja na proporção de $1: 1$ ou de $1: 2$, tampouco acrescentar carboidratos simples e/ou complexos às fórmulas infantis e ao leite de vaca com intuito de prover maior ingestáo calórica ou melhorar a palatabilidade do leite.

Em outro estudo ${ }^{16}$, em que se analisou a alimentação de lactentes saudáveis, a diluição da fórmula infantil foi correta em apenas $23,8 \%$ e $34,7 \%$ das crianças menores e maiores de seis meses, respectivamente. Os autores também verificaram o acréscimo de carboidrato simples às fórmulas infantis de $36,1 \%$ das crianças menores de seis meses, e de $54,7 \%$ das crianças maiores de seis meses. A diluição e o acréscimo de carboidratos simples no leite de vaca também estavam incorretos. Os números mostram práticas mais inadequadas em relação a este estudo, talvez pelo fato de os cuidadores de lactentes expostos ao HIV receberem, agora, orientaçóes mais enfáticas e precisas da equipe de saúde.

Convém ressaltar que o leite de vaca apresenta potencial alergênico e, por esse motivo, é recomendado para bebês apenas após o primeiro ano de vida ${ }^{17,18}$. Verificamos que mais da metade das mães introduziram o leite de vaca em momento inoportuno, antes de doze meses de vida, fato também evidenciado no estudo de Paim e Souza ${ }^{14}$, em que 26,3\% das crianças expostas ao HIV receberam leite de vaca precocemente. Tal característica pode ser explicada pelo fato de as políticas públicas no Brasil garantirem a doação de fórmulas infantis apenas até o sexto mês de vida, enquanto o ideal seria fornecê-las durante todo o primeiro ano de vida da criança. Com a interrupçáo da doação, as mães de baixa renda se veem na necessidade de oferecer o leite de vaca.

Em relação à alimentação complementar, foi possível constatar a oferta dos primeiros alimentos antes do sexto mês de vida. Tal prática contribui para o desenvolvimento de alergias e intolerâncias alimentares, diarreia e deficiência de absorçáo de nutrientes, além de subnutrição e retardo no crescimento $^{18}$. Dados similares foram observados 
em um estudo longitudinal sobre práticas alimentares de crianças amamentadas ${ }^{19}$, e em uma pesquisa com lactentes expostos ao $\mathrm{HIV}^{14}$. Além disso, outros pesquisadores ${ }^{16}$ observaram que a mediana referente à idade para a introdução da alimentação complementar na consistência de papa foi de quatro meses, e na consistência da alimentação da família, de 5,5 meses, tornando-se um agravante por dificultar o processo de mastigação, deglutição e digestão.

Segundo a recomendaçáo da Sociedade Brasileira de Pediatria (SBP), a fórmula infantil pode ser usada como fonte alimentar exclusiva para crianças até os seis meses de vida, sem a necessidade de oferecer líquidos não nutritivos, como água e chás ${ }^{18}$. Nota-se neste estudo que todos os líquidos foram introduzidos antes dos seis meses de idade, e que tal prática é frequente no Brasil, seja por crianças que recebem fórmula infantil ou que estão em aleitamento materno ${ }^{20,21}$. O fornecimento excessivo de água pode causar diluição de nutrientes e saciedade precoce, mas pode ser recomendado nos casos em que a fórmula infantil acentue a constipação intestinal dos lactentes ${ }^{18}$.

Devido ao fato de as crianças deste estudo serem maiores de seis meses, todas já deveriam ter ingerido leguminosas, carnes, ovos, legumes e verduras; mas os únicos grupos alimentares oferecidos a $100 \%$ das crianças foram os cereais, as raízes e os tubérculos, bem como as frutas - o que revela o desconhecimento das máes quanto aos alimentos que devem compor a alimentação complementar, na qual a preferência pelas fontes de carboidrato ainda é frequente. Os resultados variam entre as pesquisas, como observado em estudo ${ }^{22}$ com crianças saudáveis, as quais até oito meses de idade, em média, já tinham sido alimentadas com todos os grupos alimentares, fato que não pode ser atribuído aos aspectos socioeconômicos e demográficos maternos, visto que os resultados dessas variáveis foram semelhantes aos desta pesquisa.

Ainda foi possível verificar a ingestão elevada de ingredientes e alimentos industrializados e/ou ultraprocessados, ricos em carboidratos simples, sódio e gordura, como suco artificial, macarrão instantâneo, sal e açúcar, por lactentes menores de doze meses; além de refrigerantes, bolachas, salgados, doces e frituras por lactentes com até 24 meses de idade. Um estudo feito em três grandes cidades do Brasil com crianças saudáveis também mostrou que esses mesmos alimentos foram introduzidos antes do primeiro ano de vida ${ }^{16}$. O consumo de tais alimentos não deveria compor o cenário da alimentação de crianças menores de dois anos. Nota-se como fator agravante a introdução desses alimentos, em média, antes de doze meses de idade. O risco do surgimento de doenças crônicas não transmissíveis ainda na infância pode ser decorrente de tais práticas alimentares, principalmente em crianças expostas ao HIV, que são susceptíveis a maiores alteraçóes do estado nutricional.
Ao demonstrar as práticas inadequadas da alimentação complementar de lactentes saudáveis, Caetano et al. ${ }^{16}$ também observaram o consumo deficiente de ferro, zinco e das vitaminas B3, E e A. Os autores ressaltam a importância de os cuidadores oferecerem uma alimentação complementar saudável e diversificada, visto que ela representa uma oportunidade para expor a criança à ampla variedade de alimentos que vão formar as bases para hábitos alimentares saudáveis no futuro.

Quanto à utilização de temperos, observa-se que o sal ainda é o mais utilizado pelas famílias. Apesar do consumo satisfatório de alho, cebola e temperos naturais, a ingestão de sal, temperos industrializados e açúcar deveria ser evitada antes dos doze meses de vida, pois o consumo precoce e excessivo de sódio está associado ao desenvolvimento de hipertensão arterial, inclusive na infância, e posterior aumento do risco cardiovascular, quando adulto $^{16}$. Além disso, os temperos podem influenciar o comportamento alimentar infantil, interferindo no paladar e no desenvolvimento das preferências alimentares, fato pouco abordado por profissionais da área da saúde.

A introdução precoce da alimentação complementar, aliada ao baixo valor nutricional dos alimentos, também é responsabilidade dos profissionais da saúde, os quais estáo, por vezes, pouco preparados para fornecer orientaçóes precisas às famílias. Na prática clínica é possível observar orientaçóes incompletas e confusas, que transferem a responsabilidade e conferem total autonomia aos cuidadores. É necessário que esses profissionais estejam sempre atualizados sobre o tema e contribuam para a qualidade da alimentação infantil.

Por fim, ainda convém citar limitaçóes importantes que este estudo apresentou, como o reduzido número amostral, devido à baixa presença de lactentes em consulta ambulatorial no período da pesquisa, o que limita a abrangência do estudo; a ausência de dados antropométricos; a ausência de avaliação da alimentação cotidiana por meio de registros alimentares; e a memória das mães quanto aos alimentos já oferecidos aos filhos.

\section{Conclusão}

Práticas alimentares adequadas de lactantes que vivem com HIV, como o ato de não amamentar e a utilização de fórmulas infantis, foram pontos positivos observados no estudo. Por outro lado, evidenciaram-se práticas inadequadas, como a diluição incorreta das fórmulas infantis; a introdução inoportuna do leite de vaca e da alimentação complementar; a oferta reduzida de leguminosas, carnes, ovos, legumes e verduras; e a oferta inapropriada de alimentos industrializados e/ou ultraprocessados nos dois primeiros anos de vida. Ressalta-se que tais práticas 
inadequadas foram realizadas pela minoria das mães, mas são atos que necessitam de adequação.

Crianças expostas a doenças infectocontagiosas são vulneráveis a alteraçóes do estado nutricional, portanto, deve-se retardar ao máximo o desenvolvimento concomitante de doenças crônicas não transmissíveis, em decorrência da má alimentação. Assim, este estudo foi capaz de proporcionar conhecimento sobre as práticas atuais da alimentação de lactentes expostos ao HIV, contribuindo para as bases de evidências e para o desenvolvimento de estratégias direcionadas à redução da prevalência do consumo de alimentos ultraprocessados nos primeiros anos de vida.

\section{Referências}

1. Luzuriaga K, McQuilken P, Alimenti A, Somasundaran M, Hesselton R, Sullivan JL. Early viremia and immune responses in vertical human immunodeficiency virus type 1 infection. J Infect Dis. 1993;167(5):1008-13.

2. Brasil. Ministério da Saúde. Secretaria de Vigilância em Saúde. Programa Nacional de DST e Aids. Recomendaçóes para profilaxia da transmissáo vertical do HIV e terapia antirretroviral em gestantes. Brasília, DF: Ministério da Saúde; 2010. 172 p.

3. Lima GS, Braga TDA, Meneses JA. Neonatologia: Instituto Materno-Infantil de Pernambuco (IMIP). Rio de Janeiro: Guanabara Koogan; 2004. 400 p.

4. Silveira PP, Portella AK, Goldani MZ, Barbieri MA. Developmental origins of health and disease (DOHaD). J Pediatr (Rio J). 2007;83(6):494-504.

5. World Health Organization. The optimal duration of exclusive breastfeeding: results of a WHO systematic review. Indian Pediatr. 2001;38(5):565-7.

6. Brasil. Ministério da Saúde. Organização Pan-Americana da Saúde. Guia alimentar para crianças menores de 2 anos de idade. Brasília, DF: Ministério da Saúde; 2005. 152 p.

7. World Health Organization. Guidelines on HIV and infant feeding: principles and recommendations for infant feeding in the context of HIV and a summary of evidence. Geneva: WHO; 2010.

8. Brasil. Ministério da Saúde. Portaria no 97, de 28 de agosto de 1995 [Internet]. Diário Oficial da União. Brasília, DF; n. 166, 20 ago 1995 [citado em 2017 out 18]. Disponível em: https://goo.gl/oAGTHx

9. Lacerda EMA. Infecção pelo HIV na infância. In: Accioly E, Saunders C, Lacerda EMA. Nutrição em obstetrícia e pediatria. 2a ed. São Paulo: Cultura Médica; 2009. p. 447-64.

10. Patin RV, Palchetti CZ, Oliveira FLC. Criança e adolescente com SIDA. In: Palma D, Escrivão MAMS, Oliveira FLC, editores. Guia de nutrição clínica na infância e na adolescência. Barueri: Manole; 2009. p. 571-82.

11. Brasil. Ministério da Saúde. Secretaria de Vigilância em Saúde. Manual normativo para profissionais de saúde de maternidades: referência para mulheres que não podem amamentar. Brasília, DF: Ministério da Saúde; 2005. 32 p.

12. Fundo das Naçóes Unidas para a Infância. Como prevenir a transmissáo vertical do HIV e da sífilis no seu município. Brasília, DF: Unicef; 2008. 36 p.

13. Brasil. Ministério da Saúde. Secretaria de Vigilância em Saúde. Programa Nacional de DST e Aids. Implicaçóes éticas do diagnóstico e da triagem sorológica do HIV. Brasília, DF: Ministério da Saúde; 2004. 68 p.

14. Paim BS, Souza GC. Práticas alimentares de crianças expostas à transmissão vertical do HIV acompanhadas em quatro serviços especializados de Porto Alegre/RS. Rev HCPA. 2010;30(3):252-7.

15. Brasil. Ministério da Saúde, Secretaria de Vigilância em Saúde. Programa Nacional de DST e Aids. Protocolo para a prevenção de transmissão vertical de HIV e sífilis: manual de bolso. Brasília, DF: Ministério da Saúde; 2007. 178 p.

16. Caetano MC, Ortiz TTO, Silva SGL, Souza FIS, Sarni ROS. Complementary feeding: inappropriate practices in infants. J Pediatr (Rio J). 2010;86(3):196-201.

17. Brasil. Ministério da Saúde. Saúde da criança: nutrição infantil: aleitamento materno e alimentaçáo complementar. Brasília, DF: Ministério da Saúde; 2009. 112 p.

18. Sociedade Brasileira de Pediatria. Departamento de Nutrologia. Manual de orientação para a alimentação do lactente, do pré-escolar, do escolar, do adolescente e na escola. $3^{a}$ ed. Rio de Janeiro: SBP, 2012. 148 p.

19. Santos Neto ET, Faria CP, Barbosa ML, Oliveira AE, Zandonade E. Association between food consumption in the first months of life and socioeconomic status: a longitudinal study. Rev Nutr. 2009;22(5):675-85.

20. Audi CAF, Corrêa AMS, Latorre MRDO. Alimentos complementares e fatores associados ao aleitamento materno e ao aleitamento materno exclusivo em lactentes até 12 meses de vida em Itapira, São Paulo, 1999. Rev Bras Saúde Matern Infant. 2003;3(1):85-93.

21. Vieira GO, Silva LR, Vieira TO, Almeida JAG, Cabral VA. Hábitos alimentares de crianças menores de 1 ano amamentadas e não-amamentadas. J Pediatr (Rio J). 2004;80(5):411-6.

22. Bernardi JLD, Jordão RE, Barros Filho AA. Alimentação complementar de lactentes em uma cidade desenvolvida no contexto de um país em desenvolvimento. Rev Panam Salud Publica. 2009;26(5):405-11.

\section{Como citar este artigo:}

Queiroz PM, Lemos PC, Ued FV. Práticas alimentares e introdução da alimentação complementar de lactentes expostos à transmissão vertical do HIV. Rev. Aten. Saúde. 2017;15(53):57-65. 